\title{
Rancang Bangun Aplikasi Media Pembelajaran Bagi Siswa Penyandang Tuna Rungu Berbasis Android
} Mobile Application Engineering for Deaf Learning Support

\author{
Addin Aditya $^{1}$, Decya Windri Sukmawati Susanto ${ }^{2}$ \\ ${ }^{1}$ Program Studi Sistem Informasi, STIKI Malang \\ ${ }^{2}$ Program Studi Manajemen Informatika, STIKI Malang \\ E-mail: addin@stiki.ac.id¹,181221001@mhs.stiki.ac.id
}

\begin{abstract}
Abstrak
Masyarakat penyandang tuna rungu tentunya mengalami kesulitan saat melakukan komunikasi sehari-hari, terutama bagi para siswa tuna rungu. Sejauh ini, mereka menggunakan bahasa isyarat SIBI dalam kegiatan belajar mengajar. SIBI merupakan jenis bahasa isyarat yang banyak digunakan pada lembaga pendidikan luar biasa. Namun disatu sisi, proses belajar mengajar dinilai masih kurang maksimal apalagi dimasa pandemi. Tujuan dari penelitian ini adalah untuk membangun sebuah aplikasi berbasis smartphone sebagai media pembelajaran tambahan pengenalan huruf alphabet dan kata bagi penyandang disabilitas tuna rungu serta memudahkan mereka untuk berkomunikasi dengan sesama. Aplikasi dibuat dengan menggunakan metode waterfall, dimulai dari analisis kebutuhan, perancangan, pembuatan hingga uji coba. Penelitian ini terbatas pada pengenalan huruf alphabet dan kata dalam bahasa Indonesia serta ditujukan bagi penyandang disabilitas tuna rungu usia 7-10 tahun. Berdasarkan hasil uji ahli materi dan bahan ajar serta uji kelayakan pengguna, aplikasi ini dinyatakan layak untuk dikembangkan dengan hasil taraf kelayakan $80.45 \%$.
\end{abstract}

Kata kunci: Waterfall, Tuna Rungu, SIBI, Smartphone

\begin{abstract}
Deaf people certainly have difficulty in carrying out daily communication, especially for deaf students. So far, they use SIBI sign language in teaching and learning activities. SIBI is a type of sign language that is widely used in special education institutions. But on the one hand, the teaching and learning process is considered to be still less than optimal, especially during the pandemic. The purpose of this study is to build a smartphone-based application as an additional learning medium to recognize letters and words for deaf people and make it easier for them to communicate with other people. Applications are made using the waterfall method, starting from needs analysis, design, manufacture to testing. This research is limited to the introduction of letters of the alphabet and words in Indonesian and is intended for deaf people aged 7-10 years. Based on the results of expert tests of teaching materials and user feasibility tests, this application is declared feasible to be developed with a feasibility level of $80.45 \%$.
\end{abstract}

Keywords: Waterfall, Deaf, SIBI, Smartphone

\section{PENDAHULUAN}

Disabilitas atau yang lebih familiar disebut dengan orang yang mempunyai keterbatasan fisik merupakan sebuah isu yang sangat familiar di masyarakat Indonesia. Adapun pengertian disabilitas menurut undang-undang nomor 8 tahun 2016 adalah setiap orang yang mengalami keterbatasan fisik, intelektual, mental, atau sensorik dalam jangka waktu lama yang dalam berinteraksi dengan lingkungan dapat mengalami hambatan dan kesulitan berpartisipasi secara penuh dan efektif dengan warga negara lainnya berdasarkan kesamaan hak. Berdasarkan data 
SUSESNAS menunjukkan bahwa penyandang disabilitas tuna rungu menempati urutan kedua yang terbanyak di Indonesia. Akibat kurangnya pendengaran maka penyandang tuna rungu mengamati obyek sekitarnya melalui mata, selain melihat gerakan dan ekspresi lawan bicaranya mata penyandang tuna rungu juga digunakan untuk membaca bahasa tubuh [1].

Seiring dengan perkembangan metode pendidikan yang lebih modern maka saat ini terdapat teknologi smartphone berbasis Android yang digunakan sebagai media pembelajaran dan menawarkan berbagai macam media yang bersamaan seperti penggunaan teks, gambar, grafik, suara, video, dan animasi dapat dimanfaatkan sebagai sebuah media bantu pembelajaran yang lebih interaktif [2]. Serta telah banyak juga dikembangkan aplikasi pengenalan huruf SIBI tetapi pada aplikasi tersebut masih berupa gambar saja dalam pengenalan bahasa SIBInya serta juga masih belum adanya fitur kuis sebagai ulasan pembelajaran yang telah dipelajari.

Berdasarkan uraian di atas dapat disimpulkan pembelajaran untuk anak usia dini penyandang disabilitas tuna rungu harus diperhatikan dan disetarakan dengan anak normal lainnya. Maka dari itu dibuatlah sebuah aplikasi pengenalan huruf alfabet dan kata menggunakan bahasa isyarat SIBI bagi anak penyandang disabilitas tuna rungu yang mana aplikasi tersebut dapat dijadikan media pembelajaran tambahan yang dapat membantu meningkatkan kemampuan anak dalam menggunakan bahasa isyarat sibi. Gagasan ini juga sejalan dengan indikator tujuan nomor 4 dari Sustainable Development Goals SDGs yakni memastikan pendidikan yang inklusif dan berkualitas setara, juga mendukung kesempatan belajar semur hidup bagi semua.

\subsection{Penelitian Terkait}

Terdapat Terdapat beberapa penelitian sebelumnya yang meneliti kasus serupa yaitu memperkenalkan huruf alfabet menggunakan bahasa isyarat berbasis mobile. Adapun kajian penelitian akan diuraikan sebagai berikut.

Penelitian yang petama yang digunakan sebagai referensi penelitian berjudul Aplikasi Pengenalan Bahasa Isyarat Untuk Penyandang Tuna Rungu Berbasis Android [3]. Penelitian ini bertujuan untuk memperkenalkan bahasa isyarat kepada penyandang tuna rungu. Tetapi penelitian ini memiliki objek yang berbeda karena penelitian ini ditujukan untuk SLB dan tidak berdasarkan rentangusia nya. Kekurangan yang terdapat pada aplikasi ini terletak pada tidak adanya fitur kuis sebagai pembelajaran.

Penelitian selanjutnya adalah Aplikasi Bahasa Isyarat Pengenalan Huruf Hijaiyah Bagi Penyandang Disabilitas Tuna Runggu [4]. Penelitian ini memiliki objek dan topik yang berbeda dengan penelitian yang akan dibuat. Penelitian ini ditujukan untuk membantu penyandang tuna rungu dalam mempelajari huruf hijaiyah. Kelebihan pada penelitian ini adalah mampu memperkenalkan huruf hijaiyah kepada penyandang tuna rungu dengan menggunakan bahasa isyarat. Namun terdapat pula kelemahan dalam penelitian ini yaitu tidak adanya fitur pencarian SLB terdekat sebagai referensi sekolah bagi penyandang tuna rungu.

Penelitian berikutnya yaitu adalah Media Pembelajaran Pengenalan Huruf Alfabet Serta Bilangan Dasar Untuk Anak Tuna Rungu Dan Wicara Kelas 1 SDLB Mitra Amanda Boyolali [5].Objek dan topik yang terdapat pada penelitian ini berbeda dengan penelitian yang akan dibuat. Penelitian ini bertujuan untuk memperkenalkan alfabet serta bilangan dasar menggunakan bahasa isyarat yang ditujukan untuk anak kelas 1 SDLB . Kelemahan yang terdapat pada sistem ini terletak tidak ada fitur kuis sebagai pembelajaran dan juga pencarian SLB terdekat.

\subsection{Disabilitas dan Sistem Pendidikannya}

Menurut Kamus Besar Bahasa Indonesia (KBBI), disabilitas adalah keadaan yang merusak atau membatasi kemampuan mental dan fisik seseorang [6]. Pelabelan atau stigma yang digunakan untuk menggambarkan individu yang menyandang kecacatan sering menimbulkan kesulitan dan masalah yaitu bahwa semua orang penyandang cacat dianggap sama. Akan tetapi pada kenyataannya orang-orang yang dikelompokkan menjadi satu kelompok menurut label tertentu itu mempunyai perbedaan yang sangat besar antara individu satu dengan 
yang lainnya. Pengelompokkan tersebut berdasarkan pada prinsip melihat individu sebagai manusia, baru kemudian melihat kecacatannya. Menurut Foreman dalam buku Marlina (2015) Istilah disabilities (ketidakmampuan) adalah keterbatasan atau hambatan yang dialami oleh seorang individu sebagai akibat dari impairment (kerusakan) tertentu [7].

Tuna rungu merupakan sebuah istilah yang biasa digunakan untuk menunjukkan keadaan kehilangan pendengaran yang dialami oleh seseorang. Anak tuna rungu adalah anak yang mengalami gangguan pendengaran dan percakapan dengan derajat pendengaran bervariasi antara $15 \mathrm{~dB}-30 \mathrm{~dB}$ (mild hearing losses), $31 \mathrm{~dB}-60 \mathrm{~dB}$ (moderate hearing losses), $61 \mathrm{~dB}-$ $90 \mathrm{~dB}$ (serve hearing losses), $91 \mathrm{~dB}-120 \mathrm{~dB}$ (profound hearing losses), $121 \mathrm{~dB}$ ke atas dikatakan tuli total (total hearing losses) [8].

Pada dasarnya setiap anak berpotensi untuk memiliki permasalahan dalam belajar, hanya saja permasalahan tersebut ada yang ringan dan tidak memerlukan perhatian khusus dari orang lain karena dapat diatasi sendiri dan ada juga yang cukup berat sehingga perlu mendapatkan perhatian dan bantuan dari orang lain. Memang tidak semua anak dengan penyandang disabilitas memiliki permasalahan dalam belajar, namun ketika mereka diinteraksikan dengan anak-anak normal lainnya maka ada hal-hal tertentu yang harus mendapat perhatian khusus dari guru dan sekolah agar mendapatkan hasil belajar yang optimal [9]

Dalam paradigma pendidikan kebutuhan khusus setiap anak memiliki latar belakang kehidupan budaya dan perkembangan yang berbeda-beda oleh karena itu setiap anak memerlukan layanan pendidikan yang berbeda disesuaikan dengan hambatan belajar dan kebutuhan masing-masing anak [7].

Di Indonesia sendiri terdapat 2 jenis bahasa isyarat yang kerap digunakan yakni SIBI (Sistem Isyarat Bahasa indonesia) dan BISINDO (Bahasa Isyarat Indonesia). Bahasa SIBI merupakan bahasa isyarat yang berkembang dari serapan American Sign Language (ASL) dan merupakan cara mempresentasikan tata bahasa lisan Indonesia ke dalam UU No.2 Tahun 1989 serta dibakukan oleh Menteri Pendidikan dan Kebudayaan pada 30 Juni 1994 menjadi sistem isyarat dan masih digunakan sebagai pengantar di kurikulum Sekolah Luar Biasa (SLB). Sedangkan Bisindo adalah bahasa isyarat yang berkembang secara alami dari kaum tuna rungu di Indonesia. Sebenarnya sejak 1966 Bisindo sudah ada tetapi belum banyak dikenal oleh kaum tuna rungu, maka dari itu pemerintah menggunakan SIBI sebagai bahasa pengantar komunikasi kurikulum pada SLB [10].

\section{METODE PENELITIAN}

\subsection{Alur Penelitian}

Dalam mengembangkan sebuah aplikasi atau sistem informasi, tentunya penggunaan model sangatlah penting untuk membangun kerangka kerja agar sesuai dengan tujuan dan manfaat yang ingin dicapai. Pemilihan model yang digunakan dalam membangun sistem juga menentukan hasil dan kualitas dari produk yang akan dikembangkan serta menentukan biaya dan kebutuhan lainnya. Siklus hidup pengembangan sistem atau System Development Life Cycle (SDLC) adalah proses pembuatan dan pengubahan sistem serta model dan metodologi yang digunakan untuk mengembangkan sistem tersebut [11]. SDLC juga merupakan tahapan umum dalam pengembangan sistem. Fase umum yang dimiliki SDLC antara lain: 1. Perencanaan; 2. Analisis; 3. Implementasi; 4. Pemeliharaan.

Metode waterfall sering juga disebut dengan Linear Sequential Model. Dikarenakan model ini digambarkan mengalir dari atas ke bawah (Gambar 1), selanjutnya model ini disebut dengan waterfall atau air terjun. Model waterfall adalah contoh dari proses pengembangan berbasis perencanaan, yang pada prinsipnya pengembang harus merencanakan dan menjadwalkan seluruh proses aktivitas sebelum memulai pengerjaan [12].

Model waterfall dimulai dari menganalisis kebutuhan apa saja dari user yang perlu ada diaplikasi ini. Selanjutnya dari kebutuhan tersebut didefinisikan kebutuhan perangkat lunak dan perangkat kelas pada tahapan desain sistem. Jika sudah selesai mendefinisikan kebutuhan pengguna dan kebutuhan sistem, selanjutnya diimplementasikan dalam bentuk kode program 
dan pembuatan aplikasi. Tahapan terakhir yakni melakukan uji coba kepada pengguna untuk mengevaluasi apakah aplikasi membutuhkan perbaikan atau sudah cukup layak untuk dikembangkan. Penjabaran dari model waterfall yang digunakan pada penelitian ini adalah sebagai berikut:

1. Analisis kebutuhan

Pada tahapan ini dilakukan pengumpulan data dan informasi yang dibutuhkan untuk mendefinisikan kebutuhan perangkat lunak. Pengumpulan data dilakukan dengan cara observasi dan wawancara kepada pihak-pihak yang berkepentingan. Pada penelitian ini, dilakukan pengumpulan informasi baik melalui wawancara ataupun pengisian data melalui angket terhadap guru pengampu, siswa tuna rungu serta orang tua siswa.

2. Desain Sistem

Pada tahapan ini dilakukan pembuatan desain sistem untuk dapat mendefinisikan kebutuhan hardware yang diperlukan dalam membangun sebuah perangkat lunak. Selain itu tahapan ini juga menampilkan sistem basis data yang akan digunakan.

3. Implementasi

Pada tahap ini program sudah selesai dan siap untuk diuji coba. Pada penelitian ini aplikasi akan diuji coba kepada siswa tuna rungu, guru dan orang tua siswa.

4. Pengujian

Pada tahap ini aplikasi akan dilakukan serangkaian pengujian untuk menilai apakah aplikasi sudah memenuhi kriteria dan persyaratan sistem. Pengujian yang akan digunakan adalah uji ahli materi dan bahan ajar serta uji kelayakan pengguna dimana data pengujian akan dikumpulkan dalam bentuk kuesioner.

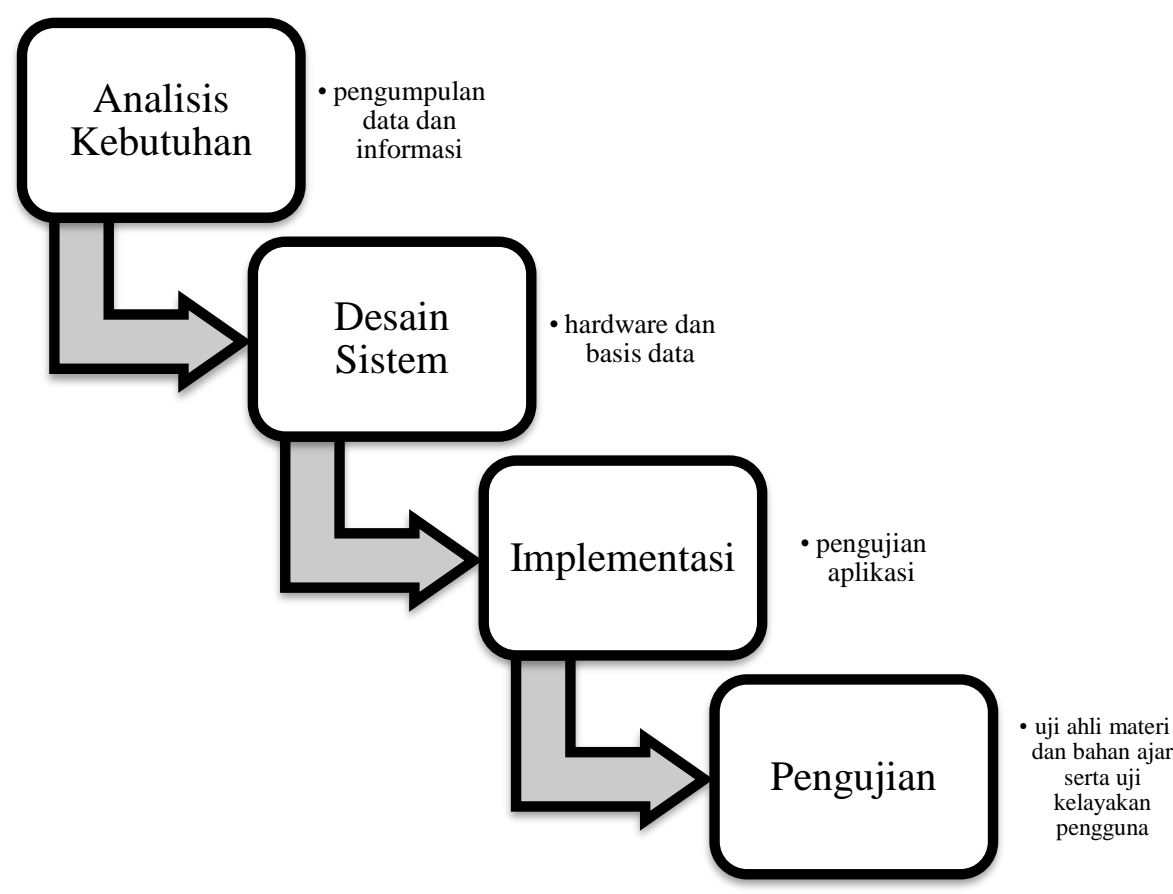

Gambar 1 Alur Penelitian Berdasarkan Adopsi Model Waterfall

\subsection{Identifikasi Masalah}

Untuk mengidentifikasi masalah yang berkaitan dengan pengenalan huruf dan kata bagi anak penyandang disabilitas tuna rungu, maka perlu dilakukan pengamatan terhadap tiga studi literatur yang membahas terkait dengan permasalahan ini. Selain itu, dilakukan juga pengambilan data dari statistik Sekolah Luar Biasa (SLB) yang diterbitkan oleh kementerian pendidikan dan kebudayaan tahun 2016/2017. Untuk menggali lebih jauh pokok permasalah ini, dilakukan wawancara dan analisa lebih lanjut dengan seorang guru di salah satu Sekolah Luar 
Biasa (SLB).

Setelah melakukan berbagai tahapan diatas, penulis menemukan bahwa terdapat beberapa masalah yang dapat disimpulkan dalam tabel kerangka PIECES sebagai berikut:

Tabel 1 Kerangka PIECES dalam Identifikasi Masalah

\begin{tabular}{|l|l|l|}
\hline \multicolumn{1}{|c|}{ Kondisi Saat Ini } & \multicolumn{1}{|c|}{$\begin{array}{c}\text { Kondisi Yang } \\
\text { Diinginkan }\end{array}$} & \multicolumn{1}{c|}{ Permasalahan } \\
\hline $\begin{array}{l}\text { Minimnya } \\
\text { pendidikan untuk } \\
\text { penyandang tuna } \\
\text { rungu. }\end{array}$ & $\begin{array}{l}\text { Pendidikan yang } \\
\text { setara antara } \\
\text { penyandang tuna } \\
\text { rungu dengan } \\
\text { masyarakat } \\
\text { normal. }\end{array}$ & $\begin{array}{l}\text { Kurangnya instansi } \\
\text { pembelajaran dan } \\
\text { tenaga pengajar. }\end{array}$ \\
\hline $\begin{array}{l}\text { Tidak semua orang } \\
\text { tua dapat } \\
\text { mengajarkan } \\
\text { pengenalan huruf } \\
\text { dan kata } \\
\text { menggunakan } \\
\text { bahasa isyarat. }\end{array}$ & $\begin{array}{l}\text { Diharapkan orang tua } \\
\text { mampu mengajarkan } \\
\text { pendidikan dasar } \\
\text { pengenalan huruf dan } \\
\text { kata dengan } \\
\text { menggunakan } \\
\text { bahasa isyarat. }\end{array}$ & $\begin{array}{l}\text { Kurangnya media } \\
\text { pembelajaran } \\
\text { pengenalan bahasa } \\
\text { isyarat yang dapat } \\
\text { digunakan untuk } \\
\text { belajar di rumah. }\end{array}$ \\
\hline
\end{tabular}

\subsection{Desain dan Perancangan}

Tahap ini menggambarkan bagaimana aplikasi pembelajaran huruf dan kata menggunakan bahasa SIBI ini dibuat. Pada tahap ini perancangan sistem UML dan tampilan mock up akan dibuat agar dapat menghasilkan desain dari aplikasi mulai dari bagaimana aplikasi akan berjalan, perancangan database hingga tampilan user interface. Pada aplikasi ini user memiliki 7 proses utama:

1. Melakukan pembelajaran Huruf

Proses ini berfungsi agar pengguna dapat melakukan pembelajaran pengenalan huruf dengan bahasa isyarat SIBI pada aplikasi.

2. Melakukan Pembelajaran Kata

Proses ini berfungsi agar pengguna dapat melakukan pembelajaran pengenalan kata dengan bahasa isyarat SIBI pada aplikasi.

3. Bermain Kuis Tebak Huruf

Use case "Bermain Kuis Tebak huruf" berfungsi agar user dapat melakukan permainan kuis tebak huruf untuk melatih kemampuan pada pengenalan huruf.

4. Bermain Kuis Tebak Kata

Use case "Bermain Kuis Tebak huruf" berfungsi agar user dapat melakukan permainan kuis tebak huruf untuk melatih kemampuan pada pengenalan kata.

5. Bermain Kuis Rangkai Huruf

Berfungsi agar user dapat melakukan permainan kuis rangkai huruf untuk melatih kemampuan merangkai huruf untuk menjadi sebuah kata.

6. Menampilkan Lokasi SLB Terdekat

Aplikasi dapat menampilkan lokasi SLB terdekat dalam bentuk peta digital

7. Menampilkan Halaman About

Aplikasi dapat menampilkan informasi profil pengembang aplikasi dalam bentuk teks 


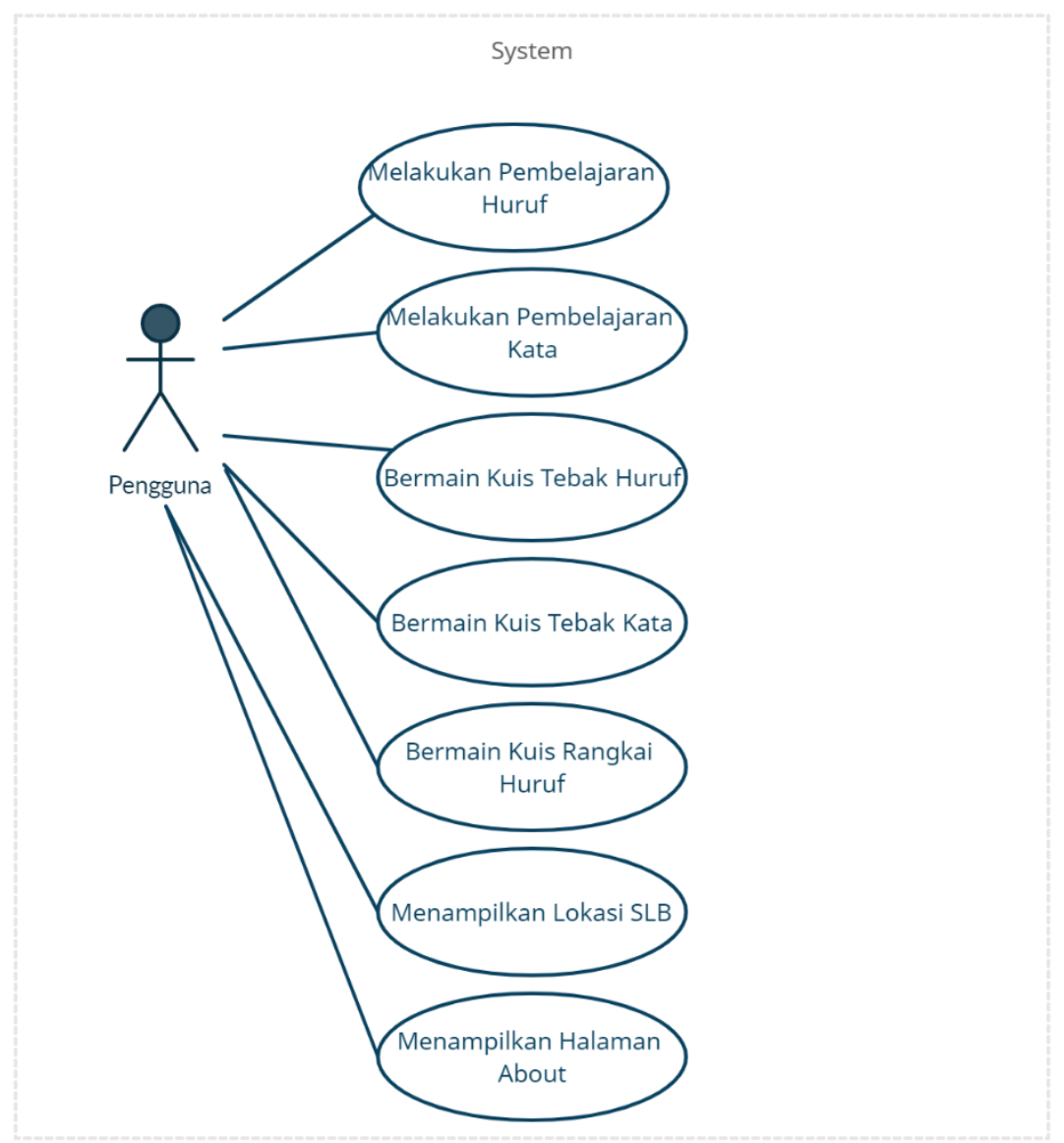

Gambar 2 Use Case Diagram Aplikasi

\section{HASIL DAN PEMBAHASAN}

\subsection{Desain Basis Data}

Pada Conceptual Data Model seperti pada Gambar 3, terdapat empat buah tabel, yaitu tebak_huruf untuk menyimpan data soal, jawaban serta nilai pada kuis tebak huruf, tebak_kata untuk menyimpan data soal, jawaban serta nilai pada kuis tebak kata, rangkai_kata untuk menyimpan data soal, jawaban serta nilai pada kuis rangkai kata, dan tabel top_score untuk menampung nilai tertinggi pada setiap kuis. 

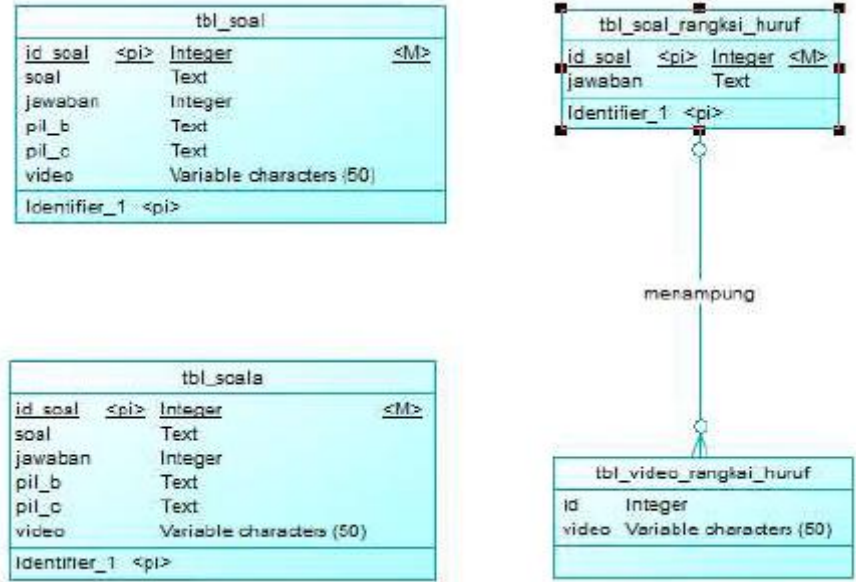

Gambar 3 Conceptual Data Model

Selanjutnya adalah Physical Data Model (PDM), dimana PDM merupakan gambaran secara detail basis data dalam bentuk fisik. Penggambaran rancangan PDM memperlihatkan struktur penyimpanan data yang benar pada basis data yang digunakan sesungguhnya.

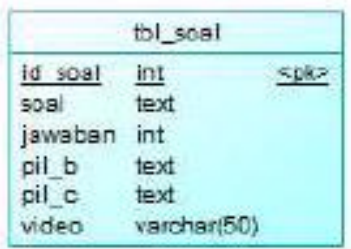

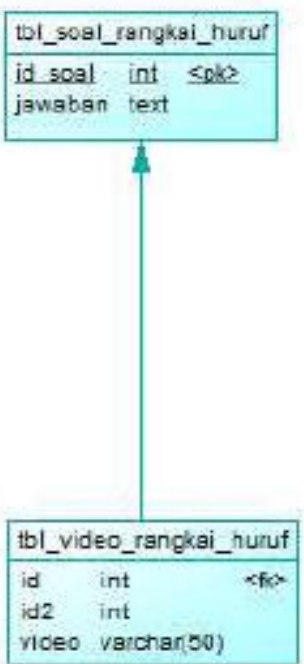

\begin{tabular}{|lll|}
\hline \multicolumn{3}{|c|}{ tbl_soala } \\
\hline id soal & int & spkp \\
\hline soal & text & \\
iawaban & int \\
pil_b & text \\
pil_c & text \\
video & varchar(50) \\
\hline
\end{tabular}

Gambar 4 Physical Data Model

\subsection{Implementasi Aplikasi}

Hasil implementasi memaparkan fitur utama dari aplikasi, yakni 1. Belajar Huruf; 2. Belajar Kata; 3. Kuis Tebak Huruf; 4. Kuis Tebak Kata; dan 5. Kuis Rangkai Huruf serta menampilkan halaman Lokasi SLB terdekat dengan peta digital.

1. Fitur Belajar Huruf

Pada halaman ini, siswa tuna rungu dapat mulai belajar untuk mengeja huruf dengan dibantu oleh video yang menggambarkan isyarat SIBI dengan gerakan tangan. 


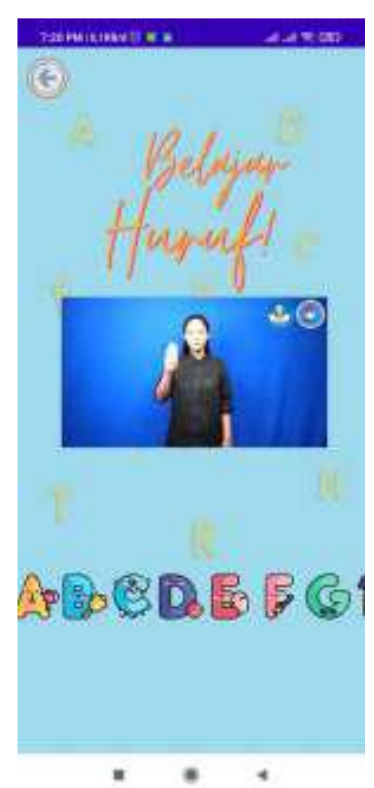

Gambar 5 Hasil Dokumentasi Fitur Belajar Huruf

\section{Fitur Belajar Kata}

Pada halaman ini, siswa tuna rungu dapat mulai belajar untuk mengeja kata dengan dibantu oleh video yang menggambarkan isyarat SIBI dengan gerakan tangan.

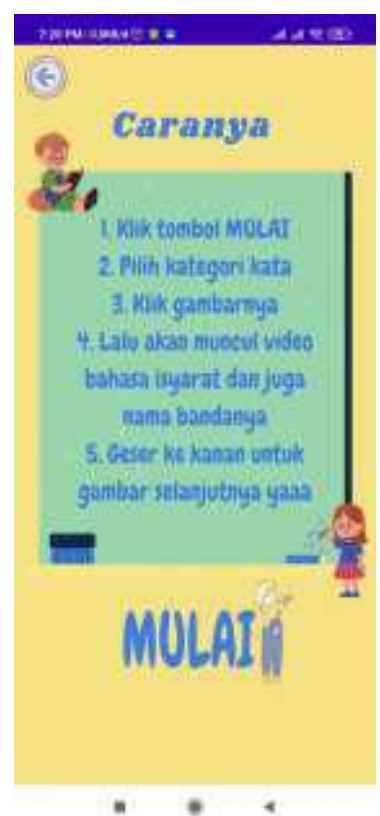

Gambar 6 Hasil Dokumentasi Fitur Belajar Kata

3. Fitur Kuis Tebak Huruf, Kata dan Rangkai Huruf

Pada fitur ini terdapat pembelajaran kata dan huruf dalam bentuk kuis. Pengguna dapat belajar untuk melakukan gerak bahasa isyarat SIBI serta mempelajari huruf dan kata melalui kuis. 


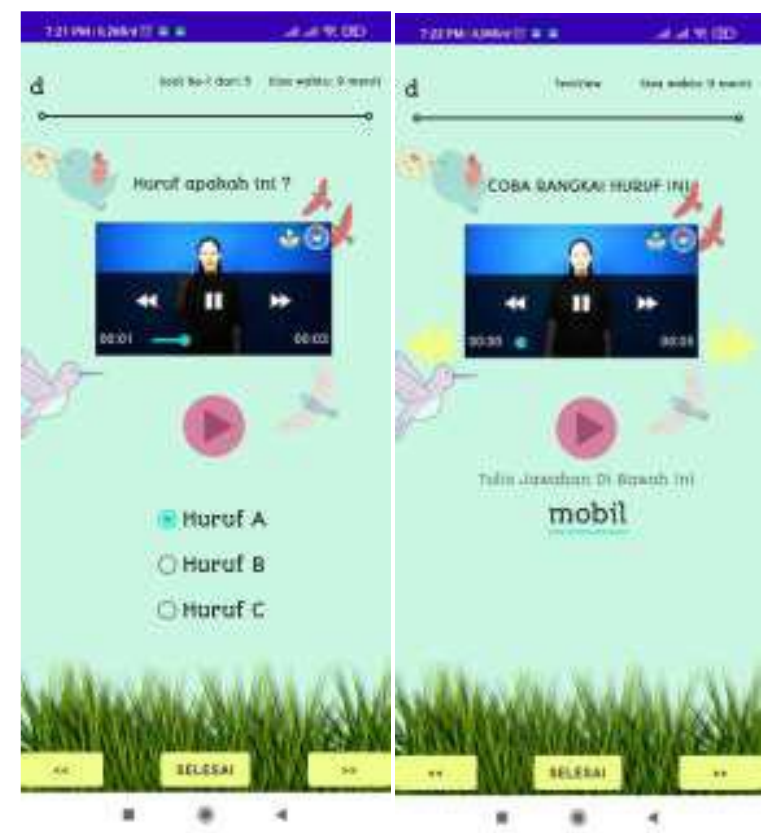

Gambar 7 Hasil Dokumentasi Fitur Kuis Tebak Huruf, Kata dan Rangkai Huruf

\section{Fitur Peta Lokasi SLB}

Pada fitur ini pengguna dapat melihat lokasi SLB yang terdekat dengan lokasi saat ini. Fitur ini ditampilkan dalam bentuk peta digital yang memanfaatkan layanan dari Google Map API

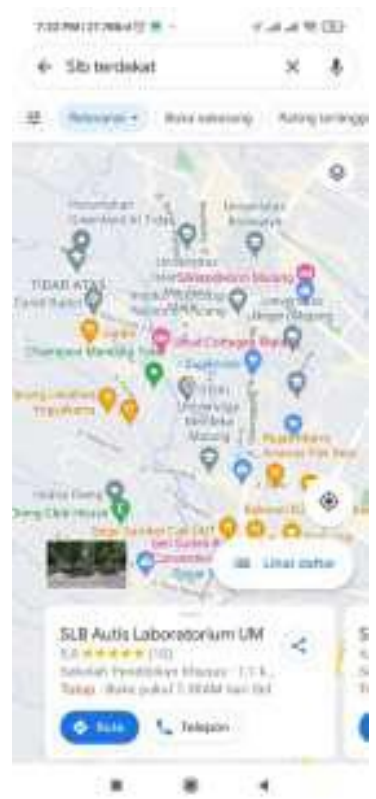

Gambar 8 Hasil Dokumentasi Fitur Lihat Lokasi SLB Terdekat

\subsection{Pengujian dan Verifikasi}

Uji coba aplikasi dilakukan dengan dua uji yaitu uji ahli materi dan bahan ajar serta uji kelayakan pengguna dimana pengumpulan data uji diperoleh melalui angket yang di isi oleh responden kemudian diolah menjadi sebuah informasi. Responden yang direncanakan terlibat dalam pengambilan data sebanyak 20 orang. Pengukuran yang dilakukan menggunakan skala Likert dengan penilaian skor sebagai berikut: 
Techno.COM, Vol. 20, No. 4, November 2021: 540-551

Tabel 2 Pengukuran Skala Likert

\begin{tabular}{|c|c|}
\hline Skala & Keterangan \\
\hline 1 & Sangat Tidak Sesuai \\
\hline 2 & Tidak Sesuai \\
\hline 3 & Netral \\
\hline 4 & Sesuai \\
\hline 5 & Sangat Sesuai \\
\hline
\end{tabular}

Aspek yang dinilai dalam uji ahli materi dan Bahan Ajar adalah Aspek Isi, Aspek Struktur Penyajian, Aspek Bahasa dan Aspek Tata Letak. Berikut adalah format kuesioner yang diisi oleh responden.

Tabel 3 Format Kuesioner Pengguna

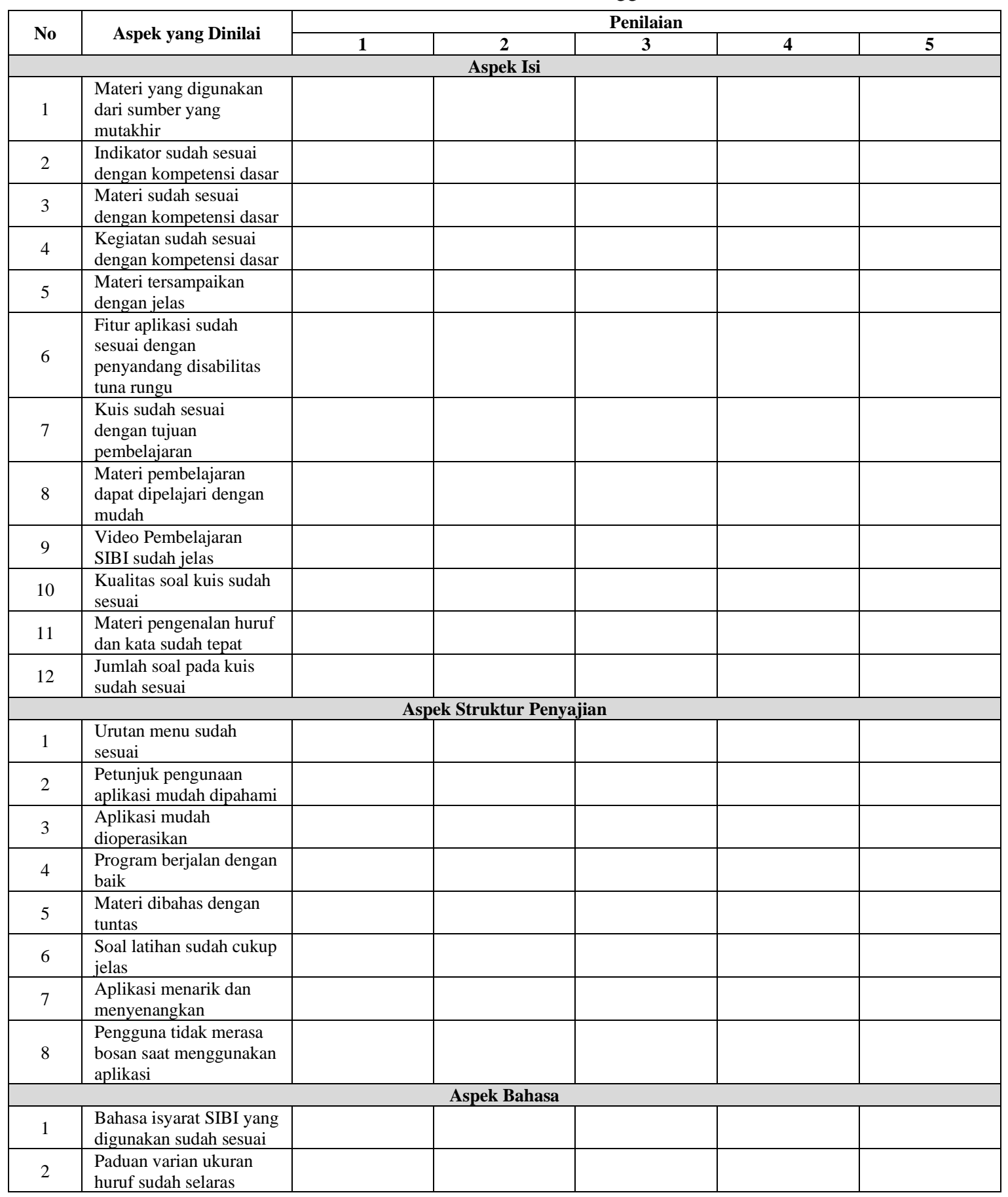




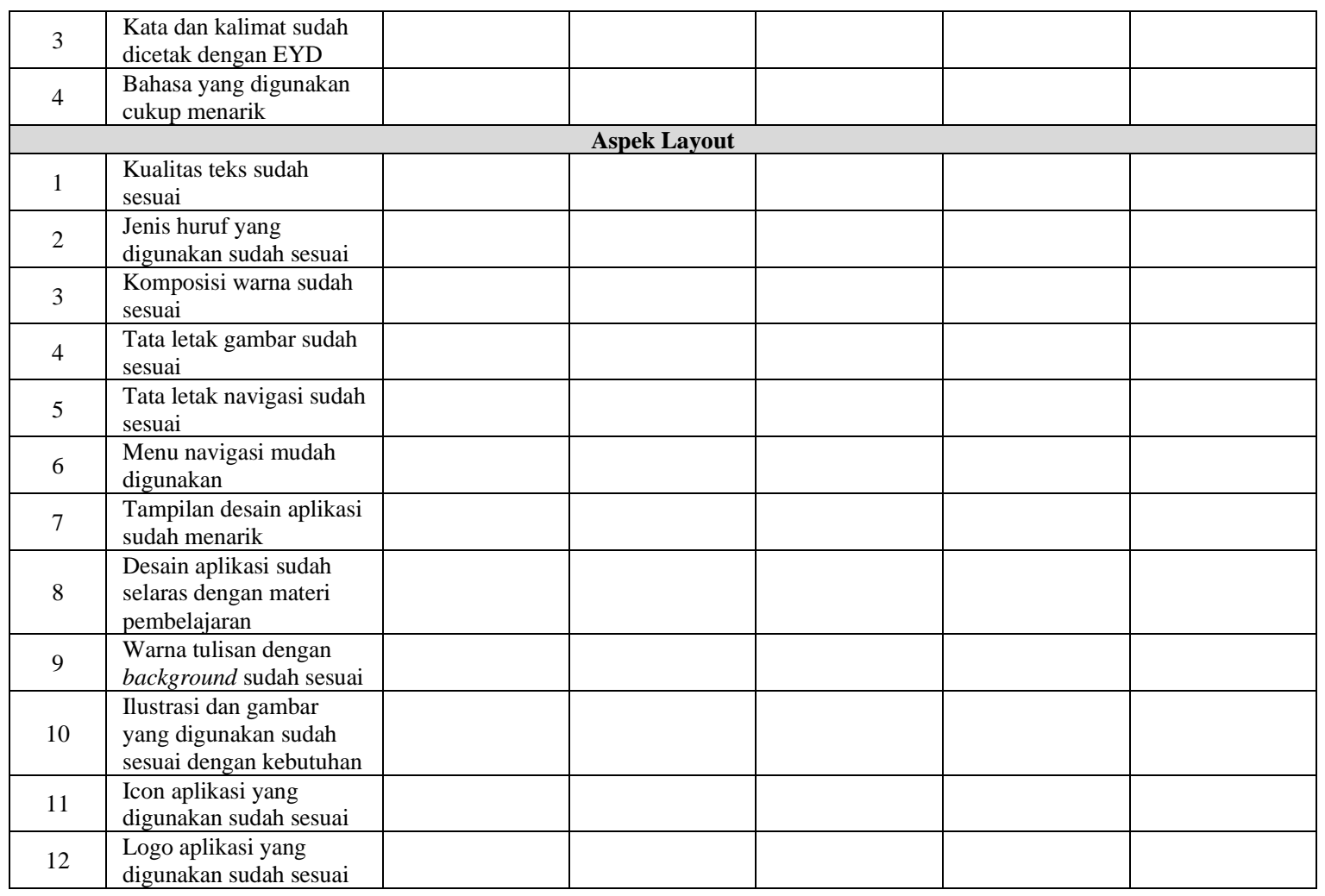

Dari hasil pengumpulan dan analisis data responden, selanjutnya akan disesuaikan dan diintepretasikan menggunakan kategori menurut Arikunto sebagai berikut [13]:

Tabel 4 Prosentase Kelayakan Implementasi Perangkat Lunak

\begin{tabular}{|c|c|c|}
\hline No & Prosentase & Keterangan \\
\hline 1 & $0 \%-19.99 \%$ & Sangat Tidak Layak \\
\hline 2 & $20 \%-39.99 \%$ & Tidak Layak \\
\hline 3 & $40 \%-59.99 \%$ & Cukup Layak \\
\hline 4 & $60 \%-79.99 \%$ & Layak \\
\hline 5 & $80 \%-100 \%$ & Sangat Layak \\
\hline
\end{tabular}

Dalam menguji kelayakan aplikasi sebagai media pembelajaran, maka dibutuhkan skala pengukuran yang sesuai. Berikut merupakan rumus dari skala pengukuran menurut Arikunto (2006).

$$
\text { presentase }=\frac{\sum(\text { jawaban } * \text { bobot tiap pilihan })}{n * \text { bobot tertinggi }} * 100 \%
$$

Dari hasil pengumpulan data angket kuesioner lalu dilanjutkan dengan pengolahan data menggunakan rumus uji kelayakan, didapatkan hasil $80.45 \%$ yang menandakan bahwa aplikasi sangat layak untuk dikembangkan dan diimplementasikan.

\section{KESIMPULAN DAN SARAN}

Berdasarkan hasil penyusunan tugas akhir, maka dapat disimpulkan bahwa dengan adanya aplikasi ini dapat menjadi media pembelajaran tambahan bahasa isyarat sibi bagi penyandang disabiliats tuna rungu. Selain itu, orang tua dapat melakukan pembelajaran bahasa isyarat sibi kepada putra putrinya dengan lebih mudah dan dapat dilakukan dimanapun. Aplikasi ini dapat mempermudah pembelajaran pengenalan huruf alphabet dan kata bagi anak penyandang disabilitas tuna rungu. Serta aplikasi ini sangat layak untuk dikembangkan dan diimplementasikan kepada seluruh siswa tuna rungu. 
Namun seperti pada umumnya bahwa setiap penelitian memiliki keterbatasan. Diharapkan untuk penelitian selanjutnya bisa menggunakan beberapa model atau kerangka kerja yang memiliki efektifitas yang lebih baik sehingga waktu pengerjaan dan hasil perangkat lunak bisa lebih baik.

\section{DAFTAR PUSTAKA}

[1] A. H. Sirait, P. Suriadireja and I. G. P. Sudiarna, "KEHIDUPAN PENYANDANG TUNA RUNGU (Studi Kasus: Keluarga "KM" di Banjar Celuk, Kelurahan Panjer, Kecamatan Denpasar Selatan," Humanis: Journal of Arts and Humanities, vol. 17, no. 1, pp. 1-6, 2016.

[2] M. H. Pradikja, H. Tolle and K. C. Brata, "Pengembangan Aplikasi Pembelajaran Bahasa Isyarat Berbasis Android Tablet," Jurnal Pengembangan Teknlogi Informasi dan Ilmu Komputer, vol. 2, no. 8, pp. 2877-2885, 2018.

[3] I. Winaldi and A. Setyawan, "Aplikasi Pengenalan Bahasa Isyarat Untuk Penyandang Tuna Tungu Berbasis Android (Studi Kasus : SLB Madina Serang)," Jurnal Sistem Informasi, vol. 5, no. 2, pp. 70-73, 2018.

[4] N. Huda, "Aplikasi Bahasa Isyarat Pengenalan Huruf Hijaiyah Bagi Penyandang Disabilitas Tuna Runggu," Jurnal Sisfokom, vol. 8, no. 1, pp. 1-6, 2019.

[5] Diharto and D. A. Anggoro, "MEDIA PEMBELAJARAN PENGENALAN HURUF ALFABET SERTA BILANGAN DASAR UNTUK ANAK TUNA RUNGU DAN WICARA KELAS 1 SDLB MITRA AMANDA BOYOLALI," UNIVERSITAS MUHAMMADIYAH SURAKARTA, SURAKARTA, 2019.

[6] Badan Pengembangan dan Pembinaan Bahasa, "Kamus Besar Bahasa Indonesia Daring (KBBI Daring)," Kementerian Pendidikan dan Kebudayaan Republik Indonesia, 2016. [Online]. Available: https://kbbi.kemdikbud.go.id/entri/disabilitas. [Accessed July 2021].

[7] Marlina, Asesmen Anak Berkebutuhan Khusus (Pendekatan Psikoedukasional), vol. II, Padang: UNP Press Padang, 2015.

[8] M. H. Pradikja, H. Tolle and K. C. Brata, "Pengembangan Aplikasi Pembelajaran Bahasa Isyarat Berbasis Android Tablet," vol. 2, no. 8, 2018.

[9] O. Dermawan, "STRATEGI PEMBELAJARAN BAGI ANAK BERKEBUTUHAN KHUSUS DI SLB," Psymphatic, Jurnal Ilmiah Psikologi, vol. VI, no. 2, pp. 886-897, 2013.

[10] T. Miskudin, "Bahasa Isyarat Menyatukan Dunia," ITJEN KEMENDIKBUD, 13 Oktober 2020. [Online]. Available: https://itjen.kemdikbud.go.id/public/post/detail/bahasa-isyaratmenyatukan-dunia. [Accessed 30 Januari 2021].

[11] R. Susanto and A. D. Andriana, "PERBANDINGAN MODEL WATERFALL DAN PROTOTYPING UNTUK PENGEMBANGAN SISTEM INFORMASI," Majalah Ilmiah Unikom, vol. 14, no. 1, pp. 41-46, 2016.

[12] I. Sommerville, Software Engineering, Boston: Pearson, 2009.

[13] S. Arikunto, Prosedur Penelitian Suatu Pendekatan Praktik, Jakarta: PT. Rhineka Cipta, 2006. 